\title{
How rational is the Greek plan for opening up tourism?
}

\section{Emmanuel N. Lazaridis* and Estelle J. Clark \\ Strategic Arrow Limited, London, UK, ECIV 2NX}

\section{Abstract}

The issue of when and how to return to business following COVID-19 lockdown is occupying the minds of policymakers, C-Suite executives and managers the world over. We are concerned by the extent to which it appears that these decisions are being taken on a wing and a prayer, while being pitched to the public as though they shouldn't be questioned. In this paper, we compare the likely impact of COVID-19 infections from travellers coming from the main countries that visit Greece, to the revenues they generate for the Greek economy. We find that arrivals from some countries should be excluded but aren't, while arrivals from other countries that are excluded perhaps shouldn't be. We show that a rational choice around limitations on the reopening of tourist markets depends on the demand for travel to Greece. We conclude that the current policy is largely economically rational, with some exceptions, but also speculate that Greece may not be ready to handle the resulting infection load.

Keywords: Health economics, Greece, tourism, COVID-19

Author Contact Details: direction @strategicarrow.com

* ORCID: 0000-0001-8593-4766 


\section{Background}

Greece has been lauded for its early and comprehensive lockdown. It's decisive actions limited the spread of COVID-19 in the country and kept deaths from the first wave of the coronavirus pandemic particularly low. [1] Anyone who came in from abroad had to comply with a two-week mandatory quarantine or risk a substantial fine, and everyone was required to self-certify their reasons for leaving home during the lockdown. As with all countries that prioritised lockdown to save lives, its successful warding off of the first wave of the pandemic has come at substantial economic cost. [2]

Tourism is a major driver of the Greek economy, especially during the summer months, so there are strong incentives to reopen the country to tourism soon. The Greek Tourism Ministry initially announced, on 29 May, a list of 29 countries from which people will be allowed to enter Greece. [3] They would be permitted to arrive on direct flights to Athens and to the northern city of Thessaloniki from 15 June. The reason given for opening to travellers from these 29 countries was that the countries had an appropriate "epidemiological profile". The USA and the UK were among the countries excluded from that list. It was also announced that the list of those eligible to enter Greece would be expanded on 1 July. Current exclusions relate to where the flight originates from and not to the traveller's nationality.

This initial announcement apparently ran into some political or diplomatic headwinds because the government later clarified its announcement to say that arrivals from outside the list of 29 countries would also be permitted, but that they would be subject to quarantine for up to 2 weeks. [4] It seems that this clarification didn't suffice because Greece then pivoted to say that it would not maintain its own list of countries approved for entry. [5] Instead, it would differentiate between arrivals from airports on a list maintained by the European Union Aviation Safety Agency (EASA) - in Annex 1 of its Safety Directives, a "list of airports located in affected areas with high risk of transmission of the COVID-19 infection" [6] - and those from elsewhere. Arrivals from the indicated airports will be required to stay overnight in a designated hotel for testing. If they test negative, they will be required to self-isolate for 
seven days. If positive, they will be placed in supervised quarantine for 14 days. Isolation will not be required for those coming from elsewhere, unless they were found to be infected upon random testing.

Meanwhile, on 2 June, Greece announced a suspension of flights to and from Qatar until mid-June, after 12 out of 91 passengers in a Qatar Airways flight that landed in Athens the previous day tested positive for the coronavirus. [7] Interestingly, Qatar Airways subsequently claimed that all the passengers on that flight had been "tested according to the procedures and established health protocols and were found fit to continue their journey" when they boarded its plane in Doha. [8] Data from the Greek National Organization for Public Health (EODY) show that in the 10-day period from May 24 to June 2, 36\% of 69 new confirmed cases were related to foreign travel. [9] This has fed concerns that Greece will face a serious challenge from new coronavirus cases over the summer.

It's obvious, therefore, that the COVID-19 infection load in Greece will increase because of tourism. The question that we haven't seen anyone address is whether, or to what extent, the plan to open Greek tourism is economically rational.

We compare the likely impact of COVID-19 infections from travellers coming from the main countries that visit Greece, to the revenues they generate for the Greek economy. We did this so that we could consider the balance between economic benefits derivable from tourism against the consequent health and mortality costs. We conclude that the current policy is largely rational, with some exceptions, but also that Greece may not be ready to handle the resulting infection load.

\section{Methods}

We obtained economic data from the Greek Tourism Confederation (SETE). SETE recently published an analysis of the country's incoming tourism market (available in Greek) that looked at the top 25 countries in terms of tourism revenue generated in 2019. [10] Each country was characterised by its importance to Greek tourism and its experience with the pandemic. The 25 
countries in the SETE analysis together cover some $87 \%$ of the market. For each country, we extracted from the SETE report its percentage of tourism revenue generated and its count of people arriving in Greece (arrivals) in 2019.

We considered the intersection of the SETE list with the initial Greek list of 29 permitted states. We then added to our analysis five of the largest contributors to tourism revenue that were excluded from the Greek list.

For each of these states, we downloaded information about the infection incidence from Our World In Data. Specifically, we obtained the 7-day rolling average estimate of daily new confirmed COVID-19 cases per million people on 31 May 2020. [11] These data are calculated from data originating with the European Centre for Disease Prevention and Control.

We calculated a relative infection load of tourism by multiplying the arrivals from each country in 2019 by the daily new confirmed COVID-19 cases per million people. Similarly, we calculated a domestic infection load for Greece using a 2019 estimate of its national population of 10.72M. We then calculated the relative infection load from domestic and foreign sources, for various assumptions in respect of the percentage of 2019 arrivals that would travel to Greece in 2020.

For simplicity, we presumed throughout our work that the 2019 relative proportions across countries of travellers and the revenues they bring to Greece would not change in 2020.

We then plotted the percentage of tourism revenue against infection load for each country on a log-log scale. All computation and plotting was done using R. Data and code are freely available upon request.

\section{$\underline{\text { Results }}$}

The intersection of the list of 29 permitted states with the SETE list consists of 15 countries and $40 \%$ of historical market share. So the initial plan around opening to tourism was structurally limited to a bit under half of the total market. Large contributors to revenue like the UK and the USA - the second and third biggest contributors to revenue - were excluded. The revised rules that 
depend on the EASA list are slightly more lenient and may permit as much as $60 \%$ of the market to function.

Figure 1 shows the plotted percentage of tourism revenue against infection load for arrivals from each country on a log-log scale. Countries in green are those in the intersection of the SETE list of top revenue contributors with the initial Greek list of 29 permitted states. Countries in red are the other largest contributors to revenues in 2019, according to the SETE data.

\section{Figure 1: Infection cost of tourism revenue}

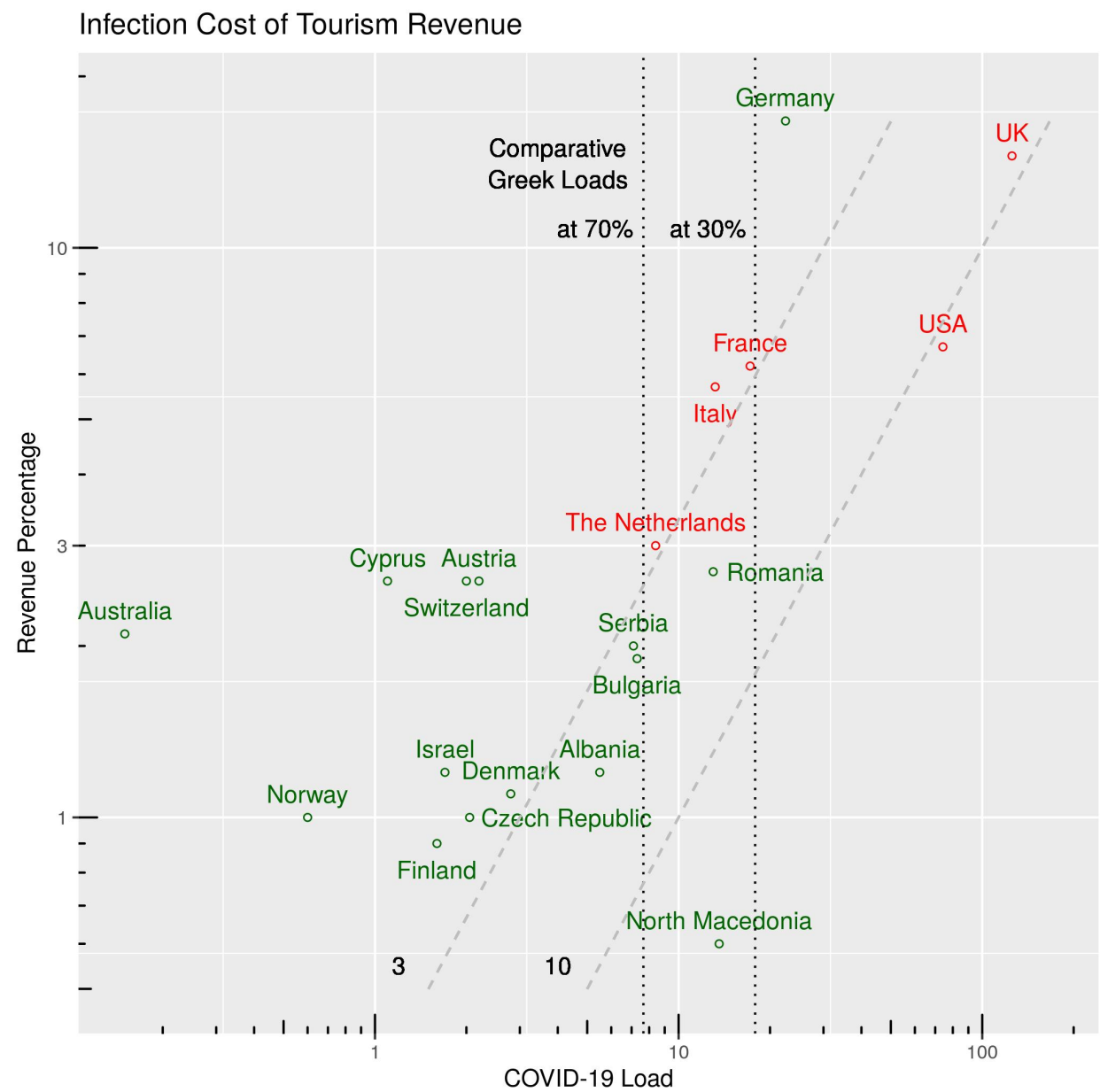

Although Germany has a better epidemiological profile (infections per million) than France or Italy, the relative infection load of Germany is likely to be higher than the infection load of either France or Italy because Germany was responsible for 2.6 times as many arrivals in 2019.

The domestic Greek infection load was 5.25 on 31 May. In Table 1 we show the total foreign infection load that would result from various combinations of 
countries, presuming that the total number of arrivals in 2020 would be the same as in 2019, for the infection incidence of 31 May.

\section{Table 1: Infection load of various combinations of countries considered}

\begin{tabular}{|l|l|l|}
\hline Set & Countries (using ISO 3166-1 alpha-3 abbreviations) & Infection Load \\
\hline Domestic & GRC & 5.25 \\
\hline Best 5 & AUS, CYP, NOR, AUT, CHE & 5.15 \\
\hline Best $5+3$ & AUS, CYP, NOR, AUT, CHE, DEU, ISR, FIN & 45.0 \\
\hline Green - 1 & AUS, CYP, NOR, AUT, CHE, DEU, ISR, FIN, DNK, CZE, SRB, BGR, ALB, ROU & 68.7 \\
\hline Green-1 +2 & AUS, CYP, NOR, AUT, CHE, DEU, ISR, FIN, DNK, CZE, SRB, BGR, ALB, ROU, ITA, FRA \\
\hline Green - 1+3 & AUS, CYP, NOR, AUT, CHE, DEU, ISR, FIN, DNK, CZE, SRB, BGR, ALB, ROU, ITA, FRA, NLD \\
\hline Red and Green - 1 & AUS, CYP, NOR, AUT, CHE, DEU, ISR, FIN, DNK, CZE, SRB, BGR, ALB, ROU, ITA, FRA, NLD, GBR, USA & 307.0 \\
\hline
\end{tabular}

The "Green - 1" set of countries corresponds to the initial Greek list of permitted countries for arrivals to Greece, excluding North Macedonia. The "Green - 1+ 2" set of countries corresponds more closely to arrivals triaged by the EASA list, again excluding North Macedonia.

Returning to Figure 1, the comparative Greek domestic infection load is indicated in two vertical dotted lines. The dotted line on the right corresponds to a proportionate 30\% of 2019 arrivals, and the line moves towards the left as the number of arrivals increases. The dotted line on the left corresponds to $70 \%$ arrivals. The more the tourism, the greater the relative proportion of infection load due to arrivals as opposed to internal Greek COVID-19 infections. For example, if arrivals from both Serbia and Bulgaria were only at 70\% of 2019 figures, these two countries alone would triple the domestic infection load. If arrivals from France were 30\% of 2019 figures, France alone would double the domestic load.

The dashed diagonal lines correspond to isobars for the cost of each percentage point of revenue against the corresponding infection load. For example, any country on the dashed line to the left is associated with a relative infection load of 3 per percentage of revenue. A country on the dashed line to the left corresponds to a value of 10. Thus, France, The Netherlands and Denmark might be expected to make a similar contribution to infection load for 
each percentage point of revenue their arrivals bring to the Greek economy. The same observation can be made for the UK and the USA.

We also calculated combined infection loads of tourism across the countries. The combined infection load of all countries in green at 30\% of 2019 arrivals would be 4.6 times the Greek national infection load. At 70\% of 2019 arrivals, it approaches 10.8 times the domestic load. At 30\% of 2019 arrivals, the infection load of countries in red would increase the domestic figure by some 13.3 times. At $70 \%$, the load from visitors flying in from red countries reaches 31 times the domestic infection load, with the USA and the UK accounting for $84 \%$ of that total. We summarise similar calculations for various combinations of countries and levels of tourism in Table 2 .

\section{Table 2: Multiplicative increase in the Greek national infection load due to arrivals from various groupings of foreign countries}

\begin{tabular}{|l|l|l|l|l|l|l|}
\hline \multirow{2}{*}{$\begin{array}{l}\text { \%-age of } \\
\mathbf{2 0 1 9} \text { Arrivals }\end{array}$} & Sets of Countries From Which Travellers Are Permitted on Direct Flights \\
\cline { 2 - 7 } & Best 5 + 3 & Green - 1 & Green - 1 + 2 & Green - 1 + 3 & Red and Green - 1 \\
\hline $30 \%$ & 0.29 & 2.6 & 3.9 & 5.7 & 6.1 & 17.5 \\
\hline $50 \%$ & 0.49 & 4.3 & 6.5 & 9.4 & 10.2 & 29.2 \\
\hline $70 \%$ & 0.69 & 6.0 & 9.2 & 13.2 & 14.3 & 40.9 \\
\hline $90 \%$ & 0.88 & 7.7 & 11.8 & 17.0 & 18.4 & 52.6 \\
\hline
\end{tabular}

Table 2 shows options for various assumptions on how 2020 tourism will stack up against 2019. Cells in green are options that keep the increase in infection load below 5 times the domestic figure. That is probably a level of increase for which Greece is prepared. Cells in yellow are combinations resulting in 5 to 10 times domestic load. It isn't obvious to us that Greece is prepared for such an increase. Cells in grey are 10 to 15 times, and the remaining cells are options that will increase the Greek national load by anything from 17 to a whopping 52.6 times. 


\section{Discussion and Conclusions}

The choice of what is an acceptable cost in terms of life and health for a specific economic gain is a political one. Government needs to have good estimates and models of the relationship between economic gains and health losses if it is to strike a balance between them. These need to be visibly used in decisionmaking. It is not acceptable for government to make decisions without a view of the consequences. Of course, there will be many people who will be unhappy with any balance that may be struck, but it is still for policymakers to take a transparent and informed decision on behalf of the governed.

We are not aware of any modelling from the Greek government akin to our very simple but informative analysis.

Our work suggests that the Greek government's plans for the reopening of tourism are not entirely rational. Arguably, arrivals from some countries should be excluded but aren't. Arrivals from other countries are excluded but perhaps shouldn't be.

For instance, many people cross into Greece from North Macedonia, but the available figures suggest that arrivals from that country bring little economic benefit relative to their corresponding COVID-19 load. We arrived at this conclusion within a day of the Greek government's announcement, and a whole five days before North Macedonia itself realised that its lockdown relaxation programme wasn't working. [12] The country reimposed tough lockdown conditions on 3 June. This may keep its people from visiting Greece for a while longer, but the issue will soon recur.

Similarly, "green" countries Albania and Romania both appear to be substantially worse for the combined Greek health and economy than do any of The Netherlands, Italy or France. All three of the latter were excluded from the initial Greek list. All flights from The Netherlands are covered by the EASA list, but regional flights from France are not excluded, and neither are flights from Rome or the southern areas of Italy. People from The Netherlands would bring relatively more revenue to Greece this summer, at less overall cost to life and health. Arguably, the Dutch should be welcomed. 
Beyond the question of whether the risks and benefits are being rationally weighed up across countries, there is also the question of how much foreign COVID-19 infection load the Greek government is willing to risk on behalf of its people. Elsewhere we argue that global tourism is best reopened by requiring travellers to self-isolate for a period of time before travel from their home countries, not upon arrival at their destination. This would truly have been the best option for Greece. The rational alternative is to estimate how many times the domestic infection load is a politically acceptable cost for the revenues to be gained, and indeed, to consider whether Greece is prepared to handle that increase.

Again, the choice of where to draw the line defining an acceptable cost to life and health is a political one. It is likely that the government will be criticised if the reopening of tourism results in a few avoidable deaths of Greek residents, but it will certainly be roasted if avoidable deaths reach into the hundreds. The government must therefore decide, on advice from its public health authorities, what increase of infection load is acceptable. It must then consider bookings and flight reservation data, advised by experts in economic statistics and tourism, to determine how many visitors to expect. These two statistics together define the country's risk tolerance. Greece can then choose what combination of allowances or restrictions on travel are likely to result in the best revenue profile, in light of the costs.

In conducting this analysis, we made no adjustments for structural issues or uncertainties in the available data, nor did we use any complex economic or epidemiological models. The infection rate per million persons is only a simple proxy metric of infection risk to the society and its health care system: it may not be perfectly comparable across countries because of differences in testing regimes; the distribution of symptomatic and asymptomatic cases across countries is unknown; cases in travellers that are not caught upon arrival may be better or worse managed than domestic Greek cases, so estimates of infection load may need some differential adjustment for testing conditions. Nor do we account for any predicted changes in infection rates as the summer progresses, or other seasonality characteristics. The rate may decrease in many countries; in others it may worsen. In respect of economics, our analysis presumes that 
arrivals from the countries we studied will be distributed with the same percentages as in 2019. We do not consider how revenues may be diminished by social distancing and other public health measures. On the other hand, the Greek government's decision to base its triage on the EASA list doesn't alter the nature of our results. At the moment, the airports on the EASA list for The Netherlands, the UK and the USA cover all or almost all of direct flight routes to Greece. We chose to stick to country-by-country analysis because we don't have data about the revenue from arrivals from particular airports. If Greece is to stick with the EASA list, it is incumbent on its experts in the ministries of finance and economic development to improve the available revenue statistics. Countries for which revenue and arrivals statistics were not available from SETE did not enter into our analysis.

An additional complexity that we have not modelled comes from the facts that local resident and traveller demographics differ in different areas of Greece, and that public health resources are not evenly distributed across them. Some tourist destinations cater to younger travellers, and some regions are home to more vulnerable people. Hard data on these differences are not available to us. It is for the public health authorities to determine whether the uneven spread of demographics and health resources in the host country significantly alters expectations around the infection load, and to advise government accordingly.

We chose to keep our approach simple because we intend this work to be expository. A simple approach often captures and communicates a large amount of information. We do not expect this analysis to be the final say on the rationality of reopening Greece to tourism. Rather, we are illustrating how Greece and other tourist markets should evaluate their options in reopening borders to tourists, in a world where very few countries have brought the pandemic to heel.

Interestingly, the EASA issued a new version (15) of its Annex 1 on 3 June, just a couple days after the Greek government's pivot to reliance on the EASA list, in which it included the following disclaimer [11] in bold type:

This list is intended to ensure an additional layer of protection for passengers and aircrew, namely the disinfection of aircraft as specified in by EASA SD 2020-01 and 


\section{SD 2020-02. The list is not intended to suggest travel restrictions or other public health measures (such as quarantine) at State level.}

The Greek government may have been looking for a scapegoat on which to hang its decision to segregate travellers by their countries of flight origin, but the EASA appears to be an unwilling participant. Policymakers must do better.

We call on the Greek government to step up and demonstrate that it has made rational and informed policy decisions around the reopening to tourism. It should support more sophisticated modelling of the trade-offs that we highlight in this paper. It should reconsider its decision to rely on the EASA list. It should monitor its own models to optimise what combination of countries should have access to the Greek tourism market while the pandemic rages, and under what conditions. It should not be afraid to modify its criteria over the course of the summer, based on both health and revenue considerations. Above all, the Greek government should use this approach to get on the front foot of its reopening policies. Intentions to react after domestic public health evidence starts to show an increase in infections are inadequate. If the government does not leverage leading indicators of infection load, it will be courting the same public health catastrophe that up until now it has successfully avoided.

We call on other countries to imitate this approach.

\section{References}

[1] Smith, H. 2020. How Greece is beating coronavirus despite a decade of debt. The Guardian. [Online]. 14 April. [Accessed 28 May 2020]. Available from: https://www.theguardian.com/world/2020/apr/14/how-greece-is-beatingcoronavirus-despite-a-decade-of-debt

[ 2 ] Papadimitriou, D. B., Nikiforos, M. and Zezza, G. 2020. Strategic Analysis: Greece's Economy after COVID-19. Levy Economics Institute of Bard College. [Online]. May. [Accessed l June 2020]. Available from:

http://www.levyinstitute.org/publications/greeces-economy-after-covid-19

[ 3 ] Bellos, I. 2020. Germany only one of Greece's big tourist markets on list of approved flights. Kathimerini. [Online]. 30 May. [Accessed l June 2020]. Available from:

https://www.ekathimerini.com/253218/gallery/ekathimerini/news/germanyonly-one-of-greeces-big-tourist-markets-on-list-of-approved-flights

[ 4 ] Associated Press and Kathimerini. 2020. Greece clarifies policy, to allow tourists from all nations. Kathimerini. [Online]. 31 May. [Accessed 3 June 2020]. 
Available from:

https://www.ekathimerini.com/253248/article/ekathimerini/news/greececlarifies-policy-to-allow-tourists-from-all-nations

[ 5 ] Bellos, I. 2020. Coronavirus checks to be conducted according to airport, not country. Kathimerini. [Online]. 2 June. [Accessed 3 June 2020]. Available from: https://www.ekathimerini.com/253296/article/ekathimerini/business/ coronavirus-checks-to-be-conducted-according-to-airport-not-country

[ 6 ] European Union Aviation Safety Agency (EASA). 2020. Operational measures to prevent the spread of Coronavirus 'SARS-CoV-2' infection, Annex 1 - Enhanced aircraft disinfection for mitigating risks of transmission of the COVID-19 infection, when operating from the areas listed below (issue 15). EASA. [Online]. 3 June. [Accessed 5 June 2020]. Available at: https://www.easa.europa.eu/SD-2020-0l/Airports

[ 7 ] Kathimerini. 2020. Greece suspends Qatar flights after 12 passengers test positive for coronavirus. Kathimerini. [Online]. 2 June. [Accessed 3 June 2020]. Available from: https://www.ekathimerini.com/253318/article/ekathimerini/news/greecesuspends-qatar-flights-after-12-passengers-test-positive-for-coronavirus

[ 8 ] Kathimerini. 2020. Qatar Airways says all passengers in Athens-bound flight were healthy in Doha. Kathimerini. [Online]. 3 June. [Accessed 5 June 2020]. Available from:

https://www.ekathimerini.com/253386/article/ekathimerini/news/qatarairways-says-all-passengers-in-athens-bound-flight-were-healthy-in-doha

[ 9 ] Bouloutza, P. 2020. Health experts wary of arrivals from abroad. Kathimerini. [Online]. 4 June. [Accessed 5 June 2020]. Available from: https://www.ekathimerini.com/253415/article/ekathimerini/news/healthexperts-wary-of-arrivals-from-abroad

[10 ] Ikkos, A., Rasouli, G., Koutsos, S. and Lamprou E. 2020. Characterisation of the markets for incoming tourism to Greece in the age of COVID-19

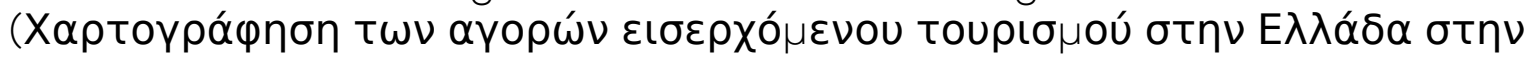

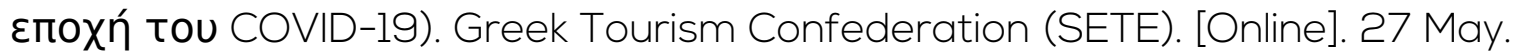
[Accessed 1 June 2020]. Available from: https://insete.gr/wp-content/uploads/ 2020/05/20-05_COVID-19_Mapping_Study.pdf

[11 ] Our World In Data. 2020. Coronavirus Pandemic Data Explorer. Data from the European Centre for Disease Prevention and Control (ECDC). [Online].

[Accessed 5 June 2020]. Retrieved from:

https://ourworldindata.org/coronavirus-data-explorer?

yScale=logkzoomToSelection=true\&casesMetric=true\&dailyFreq=true\&aligned=tr ueEperCapita=true\&smoothing $=7$

[12 ] Stamouli, N. 2020. North Macedonia experiences new spike in corona cases. Politico. [Online]. 4 June. [Accessed 6 June 2020]. Available from: https:// www.politico.eu/article/north-macedonia-experiences-new-spike-in-coronacases/ 


\section{Acknowledgements}

The authors wish to thank Azi Arman and Panagiotis Bouloumpasis for their comments on our work. 